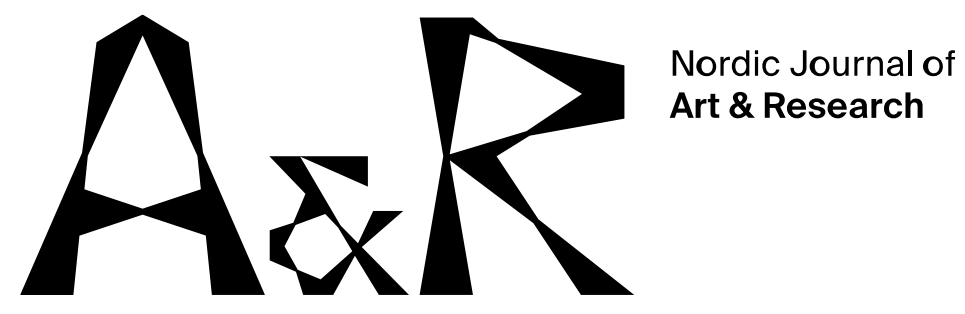

\title{
Arts for Children, Cultural Diversity and the Production of Difference
}

\author{
Jan Sverre Knudsen ${ }^{1}$ \\ Oslo Metropolitan University
}

\begin{abstract}
This article investigates policies of cultural diversity and difference in the promotion of arts to school children. Based on historical examples from concert promotion for children in Norway the article examines how cultural difference has been produced and mobilized strategically in efforts aimed at strengthening diversity. It is argued that, on the one hand, constructions of difference play an important part in the development of cultural identity and visibility, while on the other hand, a focus on difference can be a basis for cultural categorizations, and potentially, for the formation of unfortunate stereotypes. The article is informed by debates and discussions on arts for children, with reference to theorizations of difference from anthropology and education studies. Questions raised concern how difference best can be addressed in the shaping of an inclusive, anti-oppressive education.
\end{abstract}

Keywords: difference, art, education, diversity, multiculturalism

\section{Introduction}

'Good morning, pupils. You are now going to meet some exciting performers who come from a culture that is very different from ours, playing instruments that are very unfamiliar.'

These words are from the introduction given by a Norwegian headmaster to an audience of 7 - to 10-year-old school children before a school concert with Indian 
Jan Sverre Knudsen.

Arts for children, cultural diversity and the production of difference

dancer Mahua Shankar and tabla player Mithilesh Kumar. While I was conducting a study on school concerts in the county of Rogaland in Norway a few years ago (Knudsen, 2013, p. 235), I heard many similar introductions when art originating from outside the Western world was presented to school children. The aim of a concert introduction like this is obviously to draw the audience's interest and attention, to create expectations and to prepare children for what they are about to encounter. Still, as it dawned on me in my study, when it comes to presenting arts from other cultures, there is a clear tendency to highlight difference as the most important quality, often at the expense of other aspects like cultural knowledge or excellence of performance. This made me start reflecting on difference, its conceptualisation and uses.

The aim of this article is to raise some questions concerning difference in the presentation of arts to children. I will address how difference is produced, how ideas of difference work, how we may confront difference and how artists engage with difference strategically. There is a special focus on processes of categorisation in performances and in textbooks, and on the power to define and ascribe difference. I will start out with a few general and theoretical observations before I relate this to the promotion of concerts to children and to a particular project with Indian musicians. I will then discuss two contrasting approaches to difference emerging from different vantage points: difference as an idea that needs to be contested and difference as an essential cultural strategy.

\section{Questioning difference}

Over the past few years, questions of difference have become urgent and critical in both politics and education. As Tia DeNora points out in the foreword to this special issue, neoliberalism and waves of global unrest place matters of inequality front and centre stage. Against this backdrop, there is a tendency to 'reify difference into categories or identity "types" with quick resolutions'. This tendency, which lays the ground for many of the cultural and political forms of categorisation and 'othering' that we encounter on a daily basis, highlights the need for more comprehensive and nuanced ways of understanding that recognise that differences are temporal, situational cultural products with a potential to separate people but also bring them closer together. The role of musical practice and interaction in these processes is the basis of the questions of difference that this chapter engages with.

In fields relevant to art in education, there are a number of theorisations of difference. In my own deliberations, I have found inspiration in perspectives from anthropology and cultural studies that elaborate on and challenge some of the taken-for-granted 
Jan Sverre Knudsen.

Arts for children, cultural diversity and the production of difference

understandings of difference that dominate studies on cross-cultural relations. The widespread idea that social groups and communities are necessarily based on similarity, such as a common history and common practices and traditions, has increasingly been contested and nuanced. Viggo Vestel (2003) did research among 'multicultural youngsters' with highly different backgrounds. In his research entitled $A$ Community of Difference, he shows how community is constructed through musical practice in this particular youth culture. Internationalised popular music provides an arena where background, heritage and tradition become less relevant. The crucial aspect of community is the connection to music styles that are popular among young people and the musical practices developed within the group (Vestel, 2003). My own work on multi-ethnic hip-hop groups seems to confirm Vestel's arguments (Knudsen, 2011). While the young performers had different backgrounds, religions and mother tongues, these differences were not 'mobilised' in the development of the local youth culture, which was their primary identification.

Similarly, in Society of Others, Rupert Stasch (2009) challenges the 'Western' idea that unity is founded on identification and shared face-to-face experience and that ideas of community need to be based on similarity and shared experiences. Based on a study conducted in Papua New Guinnea, Stasch maintains that social engagements may be defined around ways in which people are strange to each other, not on how they perceive each other as similar. In other words, social relations are not necessarily built on notions of unity. Stasch shows us a society where people organise their connections to each other on the basis of their otherness.

The point here is that the significance of difference should not be taken for granted and will change historically and culturally. In cultural discourses in the Nordic countries today, a pronounced focus on difference in art and education can be seen as the expression of a cultural and political trend, - a politics of difference - often under the banner of cultural diversity or multiculturalism. A politics of difference acknowledges and gives status to the unique identity and practices of an individual or a group and their distinctness from everyone else. As Charles Taylor (1994) maintains, a politics of difference emerged during the last decades of the past century based on the development of a modern notion of identity. Acknowledging that everyone has an individual identity and agency, also involves the recognition of what is peculiar to each one and 'powers an acknowledgement of specificity' (Taylor, 1994, p. 39). It involves a conceptual framework that highlights and legitimises separateness and cultural distinctiveness against conceptions of the larger community, consensus and the tendency to stress common needs and interests. Consequently, a politics of difference differs from a politics of equal dignity, which, 
Jan Sverre Knudsen.

Arts for children, cultural diversity and the production of difference

according to Taylor, presumes a tight common purpose and the absence of differentiated roles, indicating that what is established 'is meant to be universally the same, an identical basket of rights and immunities' (Taylor, 1994, p. 38).

A politics of difference can also be linked to a postmodern suspicion of 'metanarratives', nationalism and unifying grand discourses in general. It seeks to shift the focus away from a presumption of sameness and common cultural heritage towards a recognition of distinctiveness, but also towards a celebration of hybridity and non-conformity with dominant cultural norms and identities. As I will argue in the further discussion, this political trend has had a considerable influence on the presentation of art to children in Norway and beyond.

My argument is based on the understanding that difference is basically a social construction. Differences are not natural, given, objective or obvious but are constructed through social discourse, policies and practices. They serve various often taken-for-granted, unspoken strategies and purposes in education and in art performance. Most importantly, differences are involved in power negotiations concerning everything, from national education plans to curricula and performances by visiting artists in schools. When working with art in education, we need to articulate questions like Who produces, ascribes and defines difference? For whom is difference necessary or useful? And to what ends?

Constructing difference starts with our perception; we notice certain sounds, sights, smells or feelings. When we experience something new, we instantaneously 'lock in' and 'shift' our attention to it, and through 'interpretive moves' we place the experience according to our pre-existing cognitive mappings and categories (Feld, 1984, p. 7). Perception emerges in relation to these culturally learned cognitive set-ups that structure our anticipation and, consequently, what we actually see or hear (DeNora, 2013, p. 107). Moreover, our anticipations and preconceptions lead us to attending to experience from the vantage point of familiarity or strangeness, which may involve labelling some of our experiences as unfamiliar or different. This spontaneous categorisation is an act of social construction.

In educational and artistic settings, it is necessary to carefully examine the consequences of thematising, configuring and promoting difference (Kumashiro, 2002). Education philosopher Nicholas Burbules (1997) suggests that we need to scrutinise what we mean by difference. He suggests that we develop a 'grammar' of difference by engaging with the various aspects that are mobilised when we characterise something as different. Among the aspects suggested by Burbules are 
Jan Sverre Knudsen.

Arts for children, cultural diversity and the production of difference

degrees, variations, versions and categories. Using examples from the music field conceptions of difference may relate to:

- Degrees - We observe more or less of a certain property. Either concrete, observable degrees of volume, tempo or complexity or more debatable degrees of for example, swing, groove, purity, western influence, appeal to children or 'danceability'.

- Variations - A well-known technique creating difference in music is the theme with variations. We elaborate, subtract or add elements to a predefined musical expression or 'object'.

- Versions - We give a musical expression a different interpretation, such as a different tone, colouring, phrasing or dynamic.

- Categories - We place experiences within a system of categories: of varieties, species or types. We place musical works, activities or performances within the boundaries of genres, historical periods or types of scales, tunes, dances or techniques. A category system can be fine or rough often depending on our knowledge of the field in question.

Engaging with these aspects of experience through cognitive, interpretive moves of differentiating, separating, shaping and managing is a fundamental strategy for learning. Without difference, there can be no meaning. The language learning of young children involves constructing categories that they can use to conceptualise and understand the world, such as by labelling and separating living things from inanimate objects. Children separate the category of animals from the category of things, and as they mature, they separate cats from dogs and eventually poodles from German shepherds. They also separate their experiences into categories, thereby constructing difference. Categorisation is a fundamental aspect of music experience, music education and concert promotion. However, as discussed later in this article, categorisations are not natural or given. There is a need to investigate and challenge common categories used to structure music promotion and education.

\section{The construction of difference in concert promotion}

The concert mentioned in the introduction of this article must be understood in light of an influential politics of difference in art and education. The concert was produced and promoted by Concerts Norway, a state organisation, which, over a period of 
Jan Sverre Knudsen.

Arts for children, cultural diversity and the production of difference

almost 50 years $^{2}$, ran a comprehensive national program of concert promotion in schools, developing a broad competence in presenting arts to children. Concerts Norway was a state-run cultural institution deeply influenced by 'multicultural' policies aimed at preserving and promoting cultural diversity in art and education. The programs were part of a Norwegian state policy, which also included the marketing of the Norwegian school concert model abroad (Knudsen, 2021). The cultural diversity efforts enjoyed strong political recognition especially from the Labour governments. This is evident in official documents. A report from the Norwegian parliament asserts that cultural diversity must be a 'permanent dimension' of all visiting artist programs in schools (KKD, 2007).

From around 1990, the concert productions began to feature distinct efforts aimed at stimulating and promoting cultural diversity. A dominating slogan that governed the policies of Concerts Norway for many years was that the aim of a school concert was to 'move, surprise and thrill' the young audiences (Berøre, overraske og begeistre) (Vandvik, 2018). Åse Kleveland, the director of Concerts Norway from 2006 to 2012, emphasised in a promotional video that the role of school concerts was to present something out of the ordinary, experiences that would stand out from the everyday school life, artistic expressions that children generally would not seek out on their own (Rikskonsertene, 2009). She argued that many children come from culturally limited backgrounds and that the purpose of holding professional concerts during school hours was to give all children something that would expand their horizons and enrich their worlds, something different.

When children (or adults for that matter) are confronted with any art performance, they immediately engage in cognitive and interpretive processes of making sense of the experience. Children attending a school concert observe intensely and may direct their attention and concentration towards any visual or aural aspect of the event. The art experience affords concentration; it structures the visual and sonic environment.

The children attending the Indian music and dance performances mentioned in the introduction to this article would notice a wide range of aspects of the performance: sounds, clothing, instruments and gestures. As I learned from my group conversations with the children and performers after the concerts, they were curious

2 From 1967 to 2016. In 2016, Concerts Norway became a part of Kulturtanken - Arts for Young Audiences in Norway, a new state institution promoting a variety of art performances in schools, not only concerts. 
Jan Sverre Knudsen.

Arts for children, cultural diversity and the production of difference

about these unusual and colourful performers. Most of them had never met Indian performers before. They had minimal cultural predispositions before the event; their knowledge of India was sparse and often limited to stereotypes (Knudsen, 2013).

When the children were invited to meet the performers after the concert, their questions and comments seemed to echo the headmaster's focus on difference in her introduction while also revolving around bodies and physical effort. Their first questions invariably focused on the unfamiliar, the strange and the extraordinary. They would ask Mahua Shankar, 'Why do you have a red mark on your forehead?' 'Why are you dancing barefoot?' 'Why are you wearing those bells on your feet?' and 'Do you really have to wear all that jewellery?' And they would ask Mithilesh Kumar, 'Does it hurt to play drums only with your fingers?'

A concert experience stimulates the production of mental imagery. Some comments from the children apparently placed the experience within familiar categories and images of India. There were associations to elephants, holy cows, turbans, gods, temples and palaces, and even to giraffes and pyramids. Many of the children's images of India referred to poverty: 'They dance barefoot because they have no shoes' and 'They have houses that fall apart easily'.

An artistic performance in school provides a space for association and reflection. Meaning in the arts is constituted reflexively, in and through the practice of articulating or connecting our experience with other things (DeNora, 2000). While novelty and difference apparently attract attention, some of the interpretive moves employed by children suggest an opposite trend, a need to anchor the art experience by connecting it to other things, often to something more familiar and secure. When talking to the Indian musicians, especially the younger children referred to people they knew or to some previous experience: 'My cousin went to India', 'I have a book about India at home', 'I have a drum like that', and 'I went to a show with my father's girlfriend, who is from Thailand'. Such comments can be labelled as 'me too' statements, so common among young children vying for attention. They reflect elaborations on an art experience that anchor it to some past experience, but they also apparently indicate a wish to enter into the positive focus surrounding the event and to share some of the status that the school concert ritual endows on the performers.

As these observations indicate, children's efforts at differentiating, separating, shaping and managing what they experience are integral to the ways in which they make sense of a meeting with the unfamiliar. Through cognitive, interpretive moves, 
Jan Sverre Knudsen.

Arts for children, cultural diversity and the production of difference

children separate new experiences into meaningful categories, constructing both connections and difference.

\section{Difference as a problem}

In the remainder of this article, I will elaborate on two separate approaches to understanding difference: firstly, a critical, postcolonial approach exploring the problems of difference related to power and cultural dominance, and secondly, a contrasting sociocultural approach exploring the strategic use of difference from the perspective of minority communities.

Kofi Agawu (2003), probably the most vigorous and critical postcolonial thinker in the field of music, argues that the construction of difference plays an important role in the building of stereotypes and negotiations of power, often through 'coarse' and 'fake' constructions of broad categories like 'African music' (Agawu, 2003, pp. 227, 231). Agawu argues that the construction of difference is the very foundation of the socalled Africanist scholarship in EuroAmerica, especially in ethnomusicology. He says that a focus on difference plays a part in cognitive and social mechanisms that can produce simplified and essentialised stereotypes, creating 'othering'. Agawu relates the construction of difference to power; defining the other as different is also an act of distancing and a condition for the asymmetric power balance implicit in the colonial discourse, which continues to play a major part in conceptualisations of the music of the African continent.

Agawu argues that there is nothing natural or self-evident in the categories put forward to distinguish African music from Western music, such as in terms of being functional as opposed to contemplative, communal rather than individualistic, spontaneous rather than calculated, rhythmically complex rather than simple, improvised rather than precomposed and so on. In a true postcolonial spirit, Agawu challenges us by simply asking, 'Is difference real?'

In the same vein and drawing on Agawu's views, Anders Rønningen (2015) points to how music textbooks in Norwegian schools fail to adequately address ambitions of cultural inclusion. Based on a comprehensive analysis of images and texts, Rønningen maintains that the tendency to present non-Western music as particularly different and exotic strengthens a stereotypical view of the other. Additionally, he maintains that this focus on difference increases the distance between a normalised majority music culture and a simplified and homogenised minority culture, whether this is called world music, ethnic music or minority music. Consequently, according to 
Jan Sverre Knudsen.

Arts for children, cultural diversity and the production of difference

Rønningen, the well-meant ambition to stimulate cultural understanding and inclusion by creating an interest in unfamiliar cultures is doomed to fail.

It could of course be argued here that difference stories 'sell better than sameness stories' even in a school textbook. Difference draws attention and stands out from the ordinary, from daily life in school. When textbook authors and teachers choose to focus on difference, it may even be understood as an effort to do away with boring teaching in the arts.

Art in education is also a market involving the buying and selling of cultural goods. The production of art for children is subject to market powers, even though the primary consumers (school children) have little real power in shaping and configuring the cultural goods they are offered. Artists performing in school projects are often freelance performers and depend on shaping their work in accordance with the expectations and demands of a market mainly governed by the concert producers. In Norway, as in many other Western countries, music and the arts are largely commodified. In this market, cultural and ethnic difference has become a commodity, potentially increasing the market value of a school concert (Comaroff \& Comaroff, 2009). When difference becomes a commodity, it has the potential to produce profit for the performers, but the marketing of difference also leads to adaptations and changes, some of which may serve to reify notions of cultural otherness (Comaroff \& Comaroff, 2009).

As discussed by Mariko Hara (2017) in her recent research, it is common for immigrant performers to adapt their styles and performances to make their musicianship fit the needs and requirements of this particular field of collaboration. The production of art performances for schools includes cultural negotiation, often between contesting educational and artistic agendas. Performers may find themselves drawn between their own artistic ambitions and the expectations of the producers they are working with. They shape their particular assemblage of artistic practice accordingly, often complying with expectations involving the highlighting of aspects of their music that are the most traditional and that are presumed to be the most unfamiliar or exotic for the school children (Hara, 2017). As Hara found in her work based on interviews with, among others, an Iranian and a Brazilian musician, there are performers who resent being constructed as different but still comply with these kinds of expectations simply out of necessity, in order to be able to sustain their livelihood as artists. However, as discussed below, minority artists may also see cultural difference as a tool that can be used strategically to claim their own ground and promote their identity. 
Jan Sverre Knudsen.

Arts for children, cultural diversity and the production of difference

\section{Difference as a necessity}

A contrasting perspective on difference has been developed in publications of Swedish music researcher Dan Lundberg, who has been involved in documenting and recording the music and dances of immigrant communities (Lundberg, Malm, \& Ronström, 2003). In a major study with other researchers on cultural diversity in Sweden, he points to the essential role of the production of difference for minority groups. According to Lundberg, difference is of key importance when it comes to making an immigrant group visible in multicultural arenas and in society at large. Also, a focus on the exclusive character of a community contributes to its internal cultural reproduction and to the construction of social boundaries surrounding it. Constructing difference is essential identity work.

As Lundberg points out, the production of difference is about being seen, heard and paid attention to in society. For minorities and other marginal communities, their selfdefinition as distinct from the surrounding world is necessary for their very survival as cultural entities. Arts are used as 'a means of expressing [that] we are different, we are an ethnic group, we have our own culture' (Ronström, 1995, p. 7). Through wise and strategic use, constructions of difference, especially of ethnic difference, have become a part of many a struggle aimed at giving a name, a voice and power to disempowered and marginalised minority groups. In our society, which at least on a political level, values and celebrates cultural diversity, being understood as different is crucial. It is the basis for the justification of minority cultures and communities as cultural entities, also opening for recognition and financial support.

For the Sámi, the indigenous people of northern Scandinavia, references to their ethnicity and culture as different have played a key role in their struggles for land rights, social rights and participation in the larger cultural and political arenas. The establishment of the Sámi parliament, museums, festivals, schools and kindergartens would be unthinkable without successful negotiations based on constructions of difference - the social construction of an indigenous people with a heritage and culture different from the more dominant cultural trends in Norway. Sámi language, Sámi textbooks and Sámi art in schools are considered indispensable in the education and upbringing of the Sámi children.

I have recently carried out a study in a Sámi kindergarten where music and visual arts play a key role in many aspects of daily life. The kindergarten is situated in a big Norwegian city, far from the core Sámi areas in the far north. It is surrounded by, but also involved in, Norwegian majority culture. In the kindergarten, Sámi symbols and ritual practices are mobilised to construct Sáminess as different from the surrounding 
Jan Sverre Knudsen.

Arts for children, cultural diversity and the production of difference

society. For all intents and purposes, a successful production of difference is the condition for the kindergarten's existence and survival. Without it, they would be culturally invisible.

Sámi symbols of art and music are integrated into the educational practices and daily routines of the kindergarten. References to reindeer, a key symbol of the Sámi people, are ubiquitous. There are reindeer horns on the walls and reindeer skins to sit on in the traditional peat hut (goahti), where the children have their lunch. The playground pavement is decorated with tracks of a reindeer calf and of an adult reindeer leading, respectively, to the kindergarten's department for the younger children and that for the older children. The kindergarten has invited various Sámi artists and performers to present Sámi music to the children. Ailos Gaup, a performer of the traditional Sámi chanting (joik), makes regular visits to the kindergarten to teach the children his joiking skills. This kindergarten obviously has a different repertoire of kindergarten music, at least different from the music culture other children in an urban environment encounter in their surroundings and in the media.

Previously in this article, I argued that difference is produced through social discourse and negotiations. Maybe this is an uncomfortable notion. Is the Sámi identity produced? Is it 'only' a social construction? Is the Sámi heritage not real? Is it not rooted in ethnicity, place and origin? Common critiques of constructionist approaches point to the 'hazard' that any issue focused on is seen as 'only' a construction as opposed to the real or objective. Speaking of how difference is produced should, however, not lead to notions of fabrication or falsity. Sáminess, Norwegianness or any other national or ethnic identity is a deeply felt, personal cultural grounding for those who connect with it. When I speak of the production of difference, I am interested in what this perspective 'does' to our thinking, how it influences our language and our practices, how it may make us suspicious of taken-for-granted assumptions and how it helps us see how categorisations and separations are shaped, maintained and propped up by textual, symbolic and artistic expressions. The sense of reality that we make is nevertheless real in its consequences.

Most importantly, addressing the production of difference challenges us to think in terms of power. If we reflect on the two perspectives on difference outlined in this article, we will realise that what distinguishes them from each other concerns where power is located: who has the power to define, categorise and differentiate through the promotion and staging of culture. The critical postcolonial stance promoted by Agawu is based on a history of domination, discrimination and 'othering'. It brings up how coarse and false categorisations can produce images that strengthen those who 
Jan Sverre Knudsen.

Arts for children, cultural diversity and the production of difference

have the power to define and control, be it through textbooks, academic publications or art performances in schools. In contrast, the difference cultivated by the Sámi kindergarten or other minority entities is a strategic self-ascription of difference vital to the maintenance and survival of the community. In other words, we need to distinguish between the external categorisation and separation imposed by producers, organisers and promoters and the differentiating practices chosen by selfascription in order to fulfil the internal cultural strategies of a community.

\section{Exploring alternatives}

Difference is not problematic in itself, but exploring how difference is produced leads us to some interesting insights and points to alternative strategies for education and art promotion. As mentioned earlier, Kofi Agawu (2003) urges us to contest and resist presumptions of difference, especially in the construction of images of African music. $\mathrm{He}$ also encourages us to consider some alternatives, notably involving what he calls a fusion of cultural horizons of understanding and the embracing of sameness. According to Agawu, 'there is no method to attend to sameness, only a presence of mind, an attitude, a way of seeing the world' (2003, p. 235). Agawu does not engage with how this worldview could be put into practice in art or education, so there obviously lies a challenge here for art educators and promoters alike. Departing from a presumed sameness rather than a presumed difference can inspire alternative strategies for presenting arts to children and may contribute to producing more inclusive, anti-oppressive art encounters in schools.

There are some noteworthy efforts in music education based on alternative understandings of culture and difference. Of particular interest are approaches that challenge common practices of categorisation. As discussed earlier, categorisation can be identified as a basis for how difference is produced and structured, as outlined in Burbules' 'grammar' of difference (Burbules, 1997). Categorisations are necessary structuring principles in education, but they are not natural or given and need to be questioned.

Two different music textbooks for schools can stand as examples. Danish art education researcher and author Eva Fock (2011) suggests that we develop new categories in art and education that are not rooted in the three most common differentiating categories used to structure music education textbooks: history, genre and place. Fock explores how we can develop trajectories that cross these categories. We might look more closely at similarities in how various forms of music work socially (in rituals, concerts or events), in how sound is produced (the physics of music), or in how music in many places around the globe can relate to or represent 
Jan Sverre Knudsen.

Arts for children, cultural diversity and the production of difference

visual artworks. Thus, in one of Fock's textbooks, Across Music (På tværs af music), there is a chapter on court music, which is illustrated with examples from Händel's Vienna, Balinese gamelan and the Gagaku music of the imperial Japanese courts. In addition, when Fock points to parallels between music and visual arts, she highlights ornamental work in sound and images, in the baroque era in Europe and in Islamic and Indonesian cultures.

Fock's alternative approach bears a striking resemblance to the work of Jonathan Kramer and Alison Arnold in their comprehensive interactive online textbook project What in the World Is Music? (Kramer \& Arnold, 2015). Just like Fock, they essentially pick apart many of the familiar structures used to organise music education and reassemble the pieces in new ways according to alternative principles of categorisation, which are not rooted in history, genre or place. The book is divided into four main chapters: The Foundations of Music, Music and Identity, Music and the Sacred, Music and Social Life, all of which give examples from a global range of styles, genres and histories.

\section{Conclusion}

This article has argued that a focus on difference can, on the one hand, be part of an empowering cultural strategy, but on the other hand, it may lay the grounds for categorisations that easily lend themselves to the development of stereotypes. By addressing the construction of difference involved in concert promotion for children, I have pointed out some alternative conceptualisations and ways of promoting music that contest and resist difference, that are more knowledge based, that presume sameness and that challenge some of the established categorisations that much of the contemporary music education is based on.

If we finally return to the school concert presentation with Indian musicians introducing this article, some questions arise: Could the presentation have been done differently? Would it be useful to frame a concert introduction in ways that avoid the dominating focus on difference? Is it possible to base a presentation on presumed sameness rather than presumed difference? Lastly, if we expand our view to the wider field of art promotion and art education, could a focus on cultural knowledge replace a focus on the different and extraordinary? How should children be prepared for encounters with new and unfamiliar art performances, and how can producers and policymakers navigate between productions of difference based on a potentially exoticising 'outside' gaze and the strategic differentiation that many immigrant performers rely on to become visible and marketable? Answering these questions requires that teachers, concert organisers and performers alike address and reflect 
Jan Sverre Knudsen.

Arts for children, cultural diversity and the production of difference

on the construction of difference and actively engage with alternative approaches to music education and concert promotion for children. This work can lay the grounds for more relevant and inclusive encounters with art in education.

\section{About the author}

Jan Sverre Knudsen is professor of music at Oslo Metropolitan University, Faculty of Education and International Studies. His research interests are related to various sub-disciplines of current musicology: music therapy, ethnomusicology, music education and the sociology of music. Knudsen has published widely on the role of musical practices in immigrant communities, amateur hip-hop performers, intercultural concert promotion in schools, and issues related to nationality and ethnicity in music education.

\section{References}

Agawu, K. (2003). Contesting difference. In M. Clayton, T. Herbert, \& R. Middleton (Eds.), The cultural study of music: A critical introduction (pp. 227-237). New York: Routledge.

Burbules, N. C. (1997). A grammar of difference: Some ways of rethinking difference and diversity as educational topics. Australian Education Researcher, 24(1), 97. https://doi.org/10.1007/BF03219643

Comaroff, J. L., \& Comaroff, J. (2009). Ethnicity, Inc. Chicago, III.: University of Chicago Press.

DeNora, T. (2000). Music in everyday life. New York: Cambridge University Press.

Feld, S. (1984). Communication, music, and speech about music. Yearbook for Traditional Music, 16, 1-18. https://doi.org/10.2307/768199

Fock, E. (2011). På tværs af musik. København: Wilhelm Hansen Musikforlag.

Hara, M. (2017). Sustaining the assemblage: How migrant musicians cultivate and negotiate their musicianship. Nordic Research in Music Education, 18, 295315.

KKD. (2007). St.meld. nr. 8 (2007-2008) A cultural rucksack for the future. Norwegian Ministry of Culture and Church Affairs.

Knudsen, J. S. (2011). Music of the multiethnic minority: A postnational perspective. MAIA - Music and Arts in Action, 3(3), 77-91.

Knudsen, J. S. (2013). Children's concert experience: An intercultural approach. In G. Boldt \& F. McArdle (Eds.), Young children, pedagogy and the arts: Ways of seeing (pp. 169-186). New York, London: Routledge. 
Jan Sverre Knudsen.

Arts for children, cultural diversity and the production of difference

Knudsen, J. S. (2021). To 'move, surprise and thrill': Thirty years of promoting cultural diversity in Norwegian school concerts. In A. Kallio, K. Marsh, S. Karlsen, E. Saether, \& H. Westerlund (Eds.), Politics of diversity in music education. Cham. Springer Open.

Kramer, J., \& Arnold, A. (2015). What in the world is music? Routledge.

Kumashiro, K. K. (2002). Troubling education: Queer activism and antioppressive education. New York: Routledge.

Lundberg, D., Malm, K., \& Ronström, O. (2003). Music media multiculture - Changing musicscapes. Stockholm: Svenskt Visarkiv.

Rikskonsertene. (2009). Mangfoldige skolekonserter [DVD].

Ronström, O. (1995). Sounds as signs. On the role of musical instruments and folk music in multicultural Sweden. In E. Stockman, A. Michel, \& B. Kjellström (Eds.), Studia instrumentorum musicae popularis (Vol. XI, pp. 91-96). Stockholm: Musikhistoriska museet.

Rønningen, A. (2015). Det etniske steget: en drøfting av kulturelt mangfold $i$ pedagogiske tekster for musikk for norsk ungdomssskole. (2015:9). Norges musikkhøgskole, Oslo.

Stasch, R. (2009). Society of others: Kinship and mourning in a West Papuan place. Berkeley: University of California Press.

Taylor, C. (1994). The politics of recognition. In A. Gutmann (Ed.), Multiculturalism: Examining the politics of recognition (pp. 25-73). Princeton, New Jersey: Princeton University Press.

Vandvik, T. (Ed.) (2018). "For barn og unge" - Utdrag fra Rikskonsertenes historie. Oslo: Akademisk publisering.

Vestel, V. (2003). A community of differences: Hybridization, popular culture and the making of social relations among multicultural youngsters in "Rudenga", East side Oslo. Institute of Social Anthropology Faculty of Social Sciences University of Oslo, Oslo. https://doi.org/10.7577/nova/rapporter/2004/15 